\title{
Characteristics and Birth Outcomes of Pregnant Women Treated with Corticosteroid After Fetal Reduction
}

\author{
I-Fang Yang ${ }^{1}$, Wei-Jiun Li ${ }^{1}$, Lee-Wen Huang ${ }^{1,2}$, Jier-Zen Chang ${ }^{1}$, Hun-Shan Pan ${ }^{1,2}$, Kenneth Pan ${ }^{3}$, \\ Cristiana $\operatorname{Pan}^{3}$ and Li-Che Lu${ }^{1 *}$ \\ ${ }^{1}$ Obstetrics and Gynecology Department, Shin Kong Wu Ho-Su Memorial Hospital, Taiwan
}

${ }^{2} \mathrm{Fu}$ Jen Catholic University, Taipei, Taiwan

${ }^{3}$ Science Department, University of British Columbia, Canada

*Corresponding author: Li-Che Lu, Department of Obstetrics and Gynecology, Shin-Kong Wu Ho-Su Memorial Hospital, \#95,

Wen-Chang Road, Shih-Lin District, Taipei, Taiwan

\section{ARTICLE INFO}

Received: 仹 June 09, 2020

Published: 慧 June 17, 2020

Citation: I-Fang Yang, Wei-Jiun Li, Lee-Wen Huang, Jier-Zen Chang, Li-Che Lu, et al., Characteristics and Birth Outcomes of Pregnant Women Treated with Corticosteroid After Fetal Reduction. Biomed J Sci \& Tech Res 28(2)-2020. BJSTR. MS.ID.004633.

Keywords: Birth Outcomes, Cerebral Palsy, Corticosteroid Therapy, Multifetal
ABSTRACT

Background and Purpose: Compared with singleton births, twin pregnancies are at increased risk of significant child morbidity, particularly cerebral palsy, after highorder fetal reduction. This is termed the vanishing-twin syndrome and is an important etiology of cerebral palsy. Antenatal corticosteroid therapy (CCT) is widely used during preterm labor to enhance lung maturity, the use of dexamethasone, however, increase the risk for detrimental long-term neurodevelopmental effects. Thus, in this study we assess the effect of CCT on neurological disability and congenital abnormality in twins over 2 years of age after fetal reduction.

Methods: The CCT (38 sets of twins) and control (56 sets) groups were compared for the incidences of cerebral palsy and congenital abnormalities, as well as mean birth weight, maternal age, and mean gestational age at delivery and at fetal reduction using records from Shin-Kong Memorial Hospital for the period 1992-2000.

Result: There were 94 quadruplet-reduced sets of twins in our study. All of these twins were alive and aged over 2 years at the time of this writing. The gestational age at the time of delivery was $32.4 \pm 2.7$ weeks for the CCT group vs. $36 \pm 2.9$ weeks for the controls, with mean birth weights of $2099 \pm 555 \mathrm{~g}$ vs. $2405 \pm 519 \mathrm{~g}$, respectively $(\mathrm{p}<0.01)$. All 94 sets of twins were delivered by cesarean section, with only 1 case ofcerebral palsy in CCT group, while the others had developed normally by the age of 2 years. Only mean birth weight and gestational age at delivery showed significant differences in comparisons of the 2 groups of twins.

Conclusion: Limiting the number of embryo transfer in essential for preventing adverse effects of the vanishing-twin syndrome. When reduction has been performed, a prolonged gestational age at delivery is mandatory for twin babies.

\section{Introduction}

Cerebral palsy, characterized by nonprogressive, abnormal control of movement or posture, is not diagnosed until months of even years after birth. Rates of learning disability and cerebral palsy are higher among twins and higher-order births than for singletons. There are several risks factors for cerebral palsy, such as multiple CCT, systemic infection, metabolic academia, acute intrapartum hypoxia, developmental abnormalities, very low birth weight, and high-order multifetal pregnancy reduction (MPR) [14]. In 1972, One study [5] described the use of corticosteroids to enhance lung maturity in preterm neonates. Despite 2 decades of controversy, however, the effect of CCT on brain development remains unresolved, and further investigation is warranted. 
Further, MPR has been introduced for reduction of fetus numbers following assisted reproductive techniques in higher-order multiple pregnancies. Non-viable fetal and placental tissue may initiate the production and release of inflammatory cytokines and induce thrombo embolization which can cause further neurological deficits [3]. In this study, therefore, we attempted to assess the birth outcomes of fetal reduction and antenatal CCT in a sample population of quadruplet-reduced twins.

\section{Maternal and Methods}

From September 1992 to March 2000, we conducted a prospective study using a sample population of 115 set of quadruplet-reduced twins born at Shin-Kong Memorial Hospital, Taipei, Taiwan. We excluded 21 sets of twins due to complications such as preterm rupture of the membrane (PROM), preeclampsia, chorioamnionitis, and twin discordance. Of the remaining 94 cases, 38 sets had received antenatal CCT due to preterm contractions; we defined this set as the CCT group, with the remaining 56 twins treated conservatively considered the control group. Neuromotor function and the incidence of congenital abnormalities were compared between the CCT and control groups. All sets of twins were delivered by cesarean section in order to diminish the number of confounding factors. Two preliminary questions were asked by phone:

a) Are either of the twins known to have cerebral palsy? If the answer was yes, 1 of the researchers conducted a further evaluation.

b) Does this child have any congenital abnormality? If the answer was yes, the type was specified,e.g., cleft palate, neural tube defect (NTD), or chromosomal abnormality.

Informed consent was obtained from each couple in the survey; preterm labor was defined as any uterine activity causing progressive cervical change at less than 37 weeks of gestational age. Frequency of corticosteroid therapy, consisting of two $12.5 \mathrm{mg}$ doses of dexamethasone (Sang-Tar, Taipei, Taiwan) administered intramuscularly 24 hours apart, ranged from a single course to a maximum of 3.Administration of more than 2 doses was deemed a multiple course. The 2 groups were compared for differences in maternal age, mean gestational age at fetal reduction, gestational age at the time of delivery, mean birth weight, and the presence of cerebral palsy and congenital abnormalities. Statistical analysis was performed using Chi-square ( $\chi 2$ ), Student's t-test, and Z test for percentages where appropriate, with $\mathrm{p}<0.01$ considered to indicate statistical significance.

\section{Result}

In total, 94 quadruplet-reduced sets of twins were enrolled in our study. At the time of the investigation, all of the twins were alive and aged older than 2 years. The mean gestational age at fetal reduction was $11 \pm 0.4$ vs. $11.3 \pm 0.6$ weeks for the CCT and control groups, respectively. Preterm contractions treated with dexamethasone occurred in 38 cases; the average number of CCT courses was 1.4 \pm 0.09 . For the CCT and control groups, respectively, the mean maternal age was $30.04 \pm 4.4$ vs. $31.02 \pm 4.6$ years; the gestational age at the time of delivery was $32.4 \pm 2.7 \mathrm{vs}$. $36 \pm 2.9$ weeks ( $p<0.01$ ); and the mean birth weight was $2099 \pm 555$ vs. $2405 \pm 519$ $\mathrm{g}(\mathrm{p}<0.01)$. All 94 sets of twins were delivered by cesearean section, with only 1 case of cerebral palsy without coagulation abnormality found in the CCT group; the others were developing normally by the age of 2 years. Mean birth weight and gestational age at delivery were the only 2 significant differences observed between the 2 groups (Table 1).

Table 1: Maternal characteristics and birth outcomes according to treatment following fetal reduction.

\begin{tabular}{|c|c|c|}
\hline \multirow{2}{*}{ No. of Twin Pregnancies (n) } & CT Group & Control Group \\
\cline { 2 - 3 } & $\mathbf{3 8}$ & $\mathbf{5 6}$ \\
\hline $\begin{array}{c}\text { Mean gestational age at fetal } \\
\text { reduction (week) }\end{array}$ & $11.1 \pm 0.4$ & $11.3 \pm 0.6$ \\
\hline Average maternal age (year) & $30.04 \pm 4.4$ & $31.02 \pm 4.6$ \\
\hline $\begin{array}{c}\text { Mean gestational age at delivery } \\
\text { (week) }\end{array}$ & $32.4 \pm 2.7$ & $36 . \pm 2.9(\mathrm{p}<0.01)$ \\
\hline Mean birth weight (g) & $2099 \pm 555$ & $2405 \pm 519(\mathrm{p}<0.01)$ \\
\hline Cesarean section & $100 \%$ & $100 \%$ \\
\hline Cerebral palsy (n/N) & $1.3 \%(1 / 76)$ & $0 \%(0 / 112)$ \\
\hline Congenital abnormalities & $0 \%$ & $0 \%$ \\
\hline
\end{tabular}

\section{Discussion}

The present report summarizes follow-up findings for a sample population of 2-year-old fetal-reduction twins enrolled in a prospective study of antenatal CCT to evaluate birth outcomes. Glucocorticoids have been used for many years to enhance lung maturity in neonates. One study [5] described the use of corticosteroids to reduce both the incidence and severity of neonatal respiratory distress syndrome. Since then, the beneficial and adverse effects of CCT have been widely discussed [2, 6-9]. Multiple CCT remains a controversial issue with respect to birth outcomes. Recently, Evans MI et al. [10] reported that antenatal dexamethasone treatment is associated with periventricular leukomalakia due to the neurotoxic effects of the corticosteroid's sulphite preservatives. Futher, Shinwell et al. [2] stated that a 3-day course of CCT in preterm infants was associated with a significantly increased incidence of cerebral palsy and developmental delay.

Therefore, Murphy et al. [11] concluded that the lack of firm evidence that antenatal corticosteroids are beneficial and the concern about potential adverse effects on fetal growth mean that the widespread administration of repeated courses of steroids to women with twin pregnancies may do more harm than good. The incidence of multiple pregnancies has increased dramatically since the introduction of an improvements in assisted reproductive techniques. Despite advances in perinatal and neonatal medicine, however, the mortality and morbidity associated with multifetal pregnancies is between 3 and 10 times that of the single variant 
[12]. Therefore, MPR was specifically developed to reduce complications associated with higher-order multiple gestations by actually decreasing fetal number [13]. Leviton and Gilles [14] suggested that remnant fetal tissues may theoretically gain access to the circulation of the remaining fetues, leading to fluctuations in fetal blood pressure and cerebral flow and, thus, initiating periventricular leukomalacia. Eli Geva et al. [15] provided further confirmation of thetheory that MPR might be an additional risk factor for periventricular leukomalacia among premature infants, regardless of twinning. Additionally, premature infants who have periventricular leukomalacia may be prone to the development of spastic diapiresis, the most common type of cerebral palsy [16]. This mechanism could be the result of an intrauterine inflammatory process caused by fetal death, which may initiate the production and release of inflammatory cytokines and induce thromboembolization [3].

Our preliminary results showed a trend towards a higher incidence of poor birth outcomes in the dexamethasone-treated group. Studies using larger sample sizes may be able to moreaccurately determine the relationship between dexamethasone treatment after fetal reduction and birth outcomes. In our study, we determined only 2 significant differences in mean gestational age at delivery and mean birth weight for the CCT group. The impact on low birth weight may have occurred due to the interval from steroids exposure to the time of delivery or preterm birth. Therefore, strategies for prevention of low birth weight may be important for further reduction of perinatal mortality and the handicaps related to low birth weight. Thus, limiting the number of embryo transfers is essential for preventing the adverse effects on birth outcomes. Despite the limitations of this investigation, it seems reasonable to suggest that our results indicate that caution with respect to limiting fetal numbers and CCT is entirely appropriate. We suggest that strict control of embryo quality and limitation of the number of embryo transfers be mandatory. Where reduction has been performed, a prolonged gestational age at delivery is important for the twin babies.

\section{Conflicts of Interest}

The authors have no conflicts of interest to declare.

\section{References}

1. Iberico G, Navarro J, Blasco L, Simon C, Pellicer A, et al. (2000) Embryo reduction of multifetal pregnancies following assisted reproduction treatment: a modification of the transvaginal ultrasound-guided technique. Hum Reprod 15: 2228-2233.
2. Smok D, Simpson LL, Shevell T, Malone F, Weintraub J, et al. (2004) Selective fetal reduction in monochorionic twin pregnancies with radiofrequency cord ablation. American Journal of Obstetrics \& Gynecology 191: S147.

3. Cheong MA, Tay SK (2014) Application of legal principles and medical ethics: multifetal pregnancy and fetal reduction. Singapore Med J 55: 298-301.

4. Haas J, Mohr Sasson A, Barzilay E, MazakiTovi S, Orvieto R, et al. (2015) Perinatal outcome after fetal reduction from twin to singleton: to\&\#xa0; reduce or not to reduce? Fertility and Sterility 103: 428-432.

5. Liu R, Miller R, Van der Veer A, Smok D, Simpson LL, et al. (2009) Abstract No. 139: Selective Fetal Reduction Using Radiofrequency Ablation in Monochorionic Multiple Gestations: Our Early Experience. Journal of Vascular and Interventional Radiology 20: S54-S55.

6. Evans MI, Andriole S, Britt DW (2014) Fetal Reduction: 25 Years' Experience. Fetal Diagnosis and Therapy 35: 69-82.

7. De Catte L, Foulon W (2002) Obstetric outcome after fetal reduction to singleton pregnancies. Prenatal Diagnosis 22: 206-210.

8. Sampson A, De Crespigny LC (1992) Vanishing twins: the frequency of spontaneous fetal reduction of a twin pregnancy. Ultrasound in Obstetrics \& Gynecology 2: 107-109.

9. Lee JR, Ku SY, Jee BC, Suh CS, Kim KC, et al. (2008) Pregnancy outcomes of different methods for multifetal pregnancy reduction: a comparative study. Journal of Korean medical science 23: 111-116.

10. Evans MI, Britt DW (2008) Fetal reduction 2008. Curr Opin ObstetGynecol 20: 386-393.

11. Nobili E, Paramasivam G, Kumar S (2013) Outcome following selective fetal reduction in monochorionic and dichorionic twin pregnancies discordant for structural, chromosomal and genetic disorders. Australian and New Zealand Journal of Obstetrics and Gynaecology 53: 114-118.

12. Blumenfeld Z, Dirnfeld M, Abramovici H, Amit A, Bronshtein M, et al. (1992). Spontaneous fetal reduction in multiple gestations assessed by transvaginal ultrasound. Br J ObstetGynaecol 99: 333-7.

13. Raviele KM, Daus K (2004) Fetal reduction from twins to a singleton: selective reduction or partial abortion? ObstetGynecol104: 1424; author reply 1424-1425.

14. Check JH, Nowroozi K, Vetter B, Rankin A, Dietterich C, et al. (1993) The effects of multiple gestation and selective reduction on fetal outcome. J Perinat Med 21: 299-302.

15. Mantzavinos T, Kanakas N, Dimitriadou F, Arvaniti K, Voutsina K, et al. (1996) Triplet pregnancy and fetal reduction counselling. Clin Exp Obstet Gynecol 23: 48-50.

16. Dadhwal V, Sharma AK, Deka D, Chawla L, Agarwal N (2019) Selective fetal reduction in monochorionic twins: Preliminary experience. J Turk Ger Gynecol Assoc 20: 79-83. 
ISSN: 2574-1241

DOI: 10.26717/BJSTR.2020.28.004633

Li-Che Lu. Biomed J Sci \& Tech Res

(C) (i) This work is licensed under Creative

Submission Link: https://biomedres.us/submit-manuscript.php

$\begin{array}{ll}\text { BIOMEDICAL } & \text { Assets of Publishing with us } \\ \text { RESEARCHES } & \text { - Global archiving of articles } \\ \text { - Immediate, unrestricted online access } & \text { - Rigorous Peer Review Process } \\ & \text { - Authors Retain Copyrights } \\ & \end{array}$

